\title{
Espaço público, visibilidade mediática e cibercultura: obliteração estrutural da esfera pública no cyberspace ${ }^{1}$
}

\author{
E nenhum rumor de água a latejar na pedra seca. \\ Apenas uma sombra medra sob esta rocha escarlate.
}

T. S. ЕLIOT (1981, p. 89).

\begin{abstract}
RESUMO
O estudo aborda a repercussão sociocultural do fenômeno da visibilidade multimediática na organização simbólica do espaço público a partir dos anos 70 do século passado, estirão histórico abrangido pela categoria da cibercultura. A argumentação é constituída em dois movimentos. O primeiro define e recontextualiza as três configurações mediáticas majoritárias do simbólico nessa época, reconhecendo-lhes o respectivo estado da arte: a cena pública de promoção e autopromoção, o espaço público de partilha e de resposta e a esfera pública de discussão, macroconfigurações que, embora imbricadas na realidade, não podem ser confundidas. Esse procedimento analítico e reflexivo condiciona o movimento sequencial da argumentação, em cujo cerne comparece a tese fundamental do texto: a obliteração estrutural e acentuada da esfera pública de discussão paradoxalmente no cyberspace, a rede de manifestação livre de idéias.
\end{abstract}

\section{PALAVRAS-CHAVE}

Cibercultura

Cyberspace

Esfera pública

\begin{abstract}
This study addresses the sociocultural repercussion of the phenomenon of multimediatic visibility in the symbolic organization of public space starting from the 1970s, a historical interval marked by the category of cyberculture. The argument comprises two approaches. The first defines and recontextualizes the three major mediatic configurations of the symbolic in this period, recognizing their respective states of the art: the public scene of promotion and self-promotion, the public space of sharing and of response, and the public sphere of discussion, which are macroconfigurations that, albeit overlapping in reality, cannot be confounded. This analytical and reflexive procedure determines the sequential movement of the argument, at whose core lies the fundamental thesis of this text: the marked structural obliteration of the public sphere of discussion paradoxically in cyberspace, the web of free manifestation of ideas.
\end{abstract}

\section{KEYWORDS}

Cyberculture

Cyberspace

Public sphere

\section{Eugênio Trivinho}

Professor do Programa de Estudos Pós-Graduados em Comunicação e Semiótica da PUC-SP/SP/BR.

eugeniotrivinho@ual.com.br 
Desde a reflexão de Habermas (1984) sobre a mutação da natureza e dinâmica públicas na fase industrial do capitalismo, a questão do espaço público, como se sabe, sofreu forte inflexão empírica e teórica. A realidade da comunicação massificada, a que se ligava fundamentalmente a crítica de Habermas, foi significativamente desconstruída com a consolidação social da Internet nas décadas de 70 e 80 e, depois, da Web, a partir dos anos 90 do século passado. $\mathrm{O}$ argumento costuma ser facilmente aceito: a emergência do cyberspace - como ficou conhecida a rede mundial de computadores a partir dos anos 80 -, na esteira sofisticada da mundialização do audiovisual e da informação em tempo real, operou nova mutação no cenário. Meios de comunicação monopolistas (estatais ou privados) cederam lugar a um opulento set de plataformas, canais e demais dispositivos de manifestação de uma miríade de vozes singulares no mundo inteiro. A centralização autocontrolada do simbólico mediático passou a conviver, relativamente arrefecida em sua exclusividade tecnológica e em seus índices de audiência, com a descentralização e aleatoriedade da atuação e expressão individuais. ${ }^{2}$

\section{A centralização autocontrolada do simbólico mediático passou a conviver, relativamente arrefecida em sua exclusividade tecnológica e em seus índices de audiência, com a descentralização e aleatoriedade da atuação e expressão individuais.}

Em palavras desdobradas, de acordo com a lógica sociocultural e política testemunhada por Habermas, vozes monopolistas privadas, revestidas de interesses comerciais inconfessos, compareciam então em contexto público para, em nome da liberdade de pensamento e de expressão, bem como da democracia formal, propor (ou impor, como se queira) interesses inconfessadamente privados, então travestidos de públicos. O cyberspace, por sua natureza interativa e individualista, com seus canais diversificados de atuação humana e manifestação de opinião, doravante postos nas mãos de milhões de indivíduos em todos os países, potencializou, ao longo de seu desenvolvimento, esse cenário, multiplicando, ao infinito, as possibilidades de inserção de vozes diferentes no contexto público. Doravante, pessoas comuns, longe da missão de trabalho e a título de expres- são livre do pensamento, providas ou não de interesses inconfessos, põem-se em contexto público, sob o usufruto da democracia como valor universal, aparentemente sem qualquer preocupação com a natureza privada ou pública dessa atuação. Parcelas importantes da outrora "periferia" ou "marginalidade" mediática (de massa) dispõem - redimida a sua exclusão social-histórica - de seus próprios meios de difusão e troca; de certa forma, é, hoje, ao seu modo, também mainstream hegemônico.

No arco temporal dos media de massa aos media interativos, vale dizer, da cultura de massa à cibercultura (aqui tomada como categoria de época, sinônima de civilização mediática avançada, organização sociotecnológica contemporânea do capitalismo tardio) (Trivinho, 2007), a rede virtual não levou às últimas consequências o espaço público moderno; antes, comparecendo-lhe empiricamente como questionamento imanente, implodiu - mister a ênfase - o seu modus operandi fundamental. Evidentemente, essa ocorrência fenomenológica acabou por comprometer, em essência, a atualidade dos próprios delineamentos teóricos de Habermas.

Não obstante, é razoavelmente aceitável, de igual modo, a tese da inexistência de motivos para qualquer entusiasmo a respeito desse recente cenário, no que concerne especificamente à temática da presente reflexão. A história sociocultural e política dos media parece, com isso, ter incorporado a ironia do tempo cíclico, a que certa vez Marx fez menção à sua maneira: paradoxalmente, o cyberspace - a rede relativamente livre de manifestação livre de idéias - faz, ele mesmo, mais ainda, réquiem a um espaço histórico, antropológico e político socialmente precioso: a esfera pública de discussão, ancorada em partilha de argumentação racional, mediante encaminhamento mútuo de propostas legítimas e verazes, reconhecidas por interlocutores que também se reconhecem legítimos e verazes, sob a égide ou não da necessidade a priori de entendimento mútuo ou consenso. ${ }^{3} \mathrm{O}$ acontecimento se põe não sem surpresas: com a consolidação social-histórica da rede, a mudança no metabolismo tecnocultural do domínio do público coincidiu - ao que tudo indica - com o questionamento empírico imanente do direito à existência dessa importante esfera de atuação.

Isto posto, convém, de partida, aprumar o diâmetro normativo da reflexão. Acolhem-se aqui, como postulados válidos, (1) a tese da decadência 
dessa esfera pública, na forma de uma rarefação progressiva, próximo de uma obliteração acentuada; e (2) a tese de que, nos casos excepcionais e efetivos de sua sobrevivência, houve decréscimo significativo da densidade e da profundidade de sua res típica, a reflexão continuada, a discussão consequente e o questionamento da estrutura e tendências do existente (voltado ou não para a sua superação). ${ }^{4}$

Deve-se igualmente reconhecer, de partida, que a questão do público sofre, na civilização tecnológica avançada, a pressão contínua de três fatores empíricos contextuais: a primeira, a lógica sociomediática da realidade glocal (nem global, nem local, antes tendência de terceira grandeza, já unitariamente efetivada em todo o planeta, e que cauciona a hibridação historicamente recente entre público e privado, próximo e distante, real e imaginário, e assim por diante); a segunda, a lógica operacional da dromocracia estrutural (o regime sociocultural invisível da velocidade como articuladora e moduladora da vida cotidiana, da subjetividade e da expressão do pensamento); e, terceiro, a lógica sociocultural da visibilidade mediática (o espaço longitudinal imaterial e invisível de circulação/migração hiperdinâmica e intermediática de signos, majoritariamente entretecida na fieira da promoção e da autopromoção de marcas, pessoas, eventos e processos) (Trivinho, 2007; 2008). Os três fatores contextuais, socialmente pantópicos, radicam na base não somente do modus operandi do que no social-histórico recente emergiu como estrutura pública (e que doravante se compreende como tal), mas também da transformação social nele e por ele implicada.

No arremate dessas duas observações, põe-se inteiro o arco da presente reflexão, encaminhada a seguir, em linhas gerais, ao modo de teses, com temáticas sinalizadas e sem aporte em casos ou situações empíricos stricto sensu (que certamente devem sobrevir no debate e assim poderão receber tratamento adequado).

\section{Cena pública, espaço público e esfera pública}

$\mathrm{Na}$ atualidade, o espaço público, no que compete tanto à sua empiria processual, quanto ao seu tratamento teórico - antes dependente da distinção básica (embora plena de sutilezas) entre o domínio do público e o domínio do privado -, vê-se funcionalmente flexionado pela existência de três configurações mediáticas majoritárias do simbólico, dotadas de características nucleares relativamente definidas (sem prejuízo de outros traços, mesmo discrepantes dos majoritários), diferentes mas conexas, dimensões que, em geral oclusas no real, no transcurso dos dias, respondem por novos e profundos deslocamentos e condensações (para evocar Freud) de sentido e operacionalidade sociocultural e que, por terem complexizado sobremaneira a matéria, urge desde logo reconhecer e circunstanciar, grosso modo: a cena pública, o espaço público e a esfera pública.

\section{Cena pública de promoção e autopromoção}

Para efeito do presente estudo, a cena pública contemporânea equivale ao macrocontexto social-histórico articulado e modulado permanentemente por fluxos tecnossimbólicos e imagéticos que perpassam a miríade de redutos glocais de acesso/recepção/retransmissão (Trivinho, 2007).

Confunde-se com a espiral de paisagens audiovisuais, ideológicas, linguageiras e pragmáticas da agenda central e periférica da visibilidade estrutural multi- e intermediática (Trivinho, 2008), isto é, a configuração cultural egressa da produção diuturna, excessiva e reciclável dos media (de massa, interativos e híbridos) e fincada no mercado glocal das audiências. Aberta, de caráter universalizado - válida para todos os sujeitos, instituições, corporações e demais instâncias sociais -, de célere processamento informacional de acontecimentos e fatos que doravante marcam, com sinete de fogo, a experiência coletiva e individual, a cena pública hodierna equivale a uma protuberância cultural fincada no cruzamento inextricável entre a produção mediática de massa e a produção digital, vale dizer, interprodução sígnica pantópica, autorreferencial, tão saturada quanto confusa, desprovida de centro diretor unitário, de organicidade interna e de finalidade histórica e cultural.

Assenta-se, em suas veias, o murmúrio socialmente profuso, nutrido por todos os focos de burburinho e que vive intensamente tanto dos interstícios dos dias (ao simultaneamente construí-los), e a cada dia contabilizado a dedo, quanto do esquecimento necessário e da lembrança conveniente, regados pela flutuação das audiências, para validar, nos dias seguintes, a mesma estrutura de roda-viva, em procedimento non-stop circunstância nunca superável que redunda no grande ruído civilizatório que se pretende (ou que se intende pretensamente como) a própria e única realidade contemporânea, organizadora de todas as subjetividades, produções e processos. Tecido hipersensível de ressonância mediática de ações autopromocionais dos governos, corporações, enti- 
dades civis e agentes individuais, a cena pública se converteu, propriamente, no que doravante se compreende - à falta de melhor nomenclatura congênere - como "sistema" ou "o" social como contexto e processo estruturalmente instaurados e normalizados, ou melhor nomenclatura congênere.

A cena pública é, igualmente, a macroesteira comunicacional da irreverência, do deboche e do escarnecimento lúdico e despropositado como instrumentos de violência imaterial; da chantagem e da dissuasão coletiva, do terrorismo simbólico e do linchamento incorpóreo (doloso ou implícito, premeditado ou não) da alteridade e de sua imagem.

Com baixa taxa de racionalidade ponderativa vis-à-vis alto índice de emotividade e, portanto, de condutibilidade estésica, afeita em tudo ao sensacionalismo, e ressonante ao choque e comoção coletivos, essa cena é o pródigo reino das estratégias de aparecimento e desaparecimento como forma de poder (Trivinho, 1998), das reações imediatas voltadas majoritariamente para a promoção e autopromoção, estando, pois, disponível para intervenções de todo tipo, na forma de investidas (quase sempre planejadas) de colonização e povoamento (permanentes ou temporárias) das redes e, por ela, do imaginário social, bem como de produção de jogos de cena institucionais e pessoais, de factóides políticos e comerciais, de manipulação noticiosa e estatística, e assim por diante.

Valha o friso: nesse cenário, todas as ações e atuações tendem a se reduzir à cantilena dita, da promoção e autopromoção (seja qual for o elemento valorado), à semelhança de um fio que perpassa a cerzidura inteira e, ao mesmo tempo, silenciosamente, com matiz ostensivo, a caracteriza. Domínio do código do entretenimento, ${ }^{5}$ a cena pública é, igualmente, a macroesteira comunicacional da irreverência, do deboche e do escarnecimento lúdico e despropositado como instrumentos de violência imaterial; da chantagem e da dissuasão coletiva, do terrorismo simbólico e do linchamento incorpóreo (doloso ou implícito, premeditado ou não) da alteridade e de sua imagem.

O glamour e o frenesi que lhe talham, com força insondável, o aspecto sedutor e motivacional para o olhar comum constituem apenas ares di- versionistas que engalanam e, simultaneamente, camuflam uma disputa intestina inelidível por espaço de espécie típica, próprio do contexto mediático, a saber, um espaço-tempo, traduzido lato sensu como tempo de superexposição (Virilio, 1993a; 1993b), na modalidade de um jogo social de violência simbólica pouco notada, de obtenção de êxito e fama e, por isso, ao mesmo tempo, de imposição de morte simbólica ao outro: a atração para si ou para a produção própria de maior índice de atenção pública ofusca, voluntária ou involuntariamente, não raro de modo ostensivo - é o traço hegemônico do contexto -, a intenção ou cartada alheia.

Não subsiste outra razão senão esta para a sua característica mais imperceptivelmente impetuosa: a cena pública - a se lembrar, a visibilidade mediática - é o locus panorâmico de uma concorrência interssígnica agonística, voltada para a transformação da superexposição e da (auto)promoção em realidade crônica, estável, seja no maintream multimediático ou em suas adjacências relevantes, seja naquele socialmente setorial (como é o caso de media regionais ou contextos online específicos, como o Orkut, o YouTube, o Second Life e o Twitter), sujeitas a ajustes de praxe, sobretudo pela fabricação de ausências sazonais ou desaparecimentos duradouros, a título de valorização condicional da restauração posterior da presença, ou melhor, do objeto da estratégia de (auto) promoção.

A natureza dessa dinâmica sígnica, em tudo alterflageladora e, em geral, desprovida de grito audível e dor aparente, não esconde, assim, o seu estofo histórico-cultural regressivo, bastante ativo em sua pulsação subreptícia: a cena pública, assim candidamente urdida pela regra consuetudinária e agonística do fazer ser e do existir no sentido exclusivamente mediático, é fomentada pela lógica da guerra; ela é a forma audiovisual mais desenvolvida e, ao mesmo tempo, obliterada da guerra no âmbito do simbólico.

Para a sociedade civil organizada, para os agentes politizados do espaço público, para a subjetividade participativa, engajada na construção do real comum, a cena pública envolve acontecimentos, fatos e processos que se apresentam tanto no "núcleo" mais recorrente da visibilidade mediática regional, nacional e internacional, quanto em sua periferia, seja na modalidade de temática com valor socialmente depreciado, seja na forma de experiências cotidianas não mediatizadas. Não obstante, para milhões de pessoas 
no mundo inteiro, essa cena se reduz, exclusiva e paradoxalmente, ao que se processa, de ponta a ponta, na visibilidade mediática (na realidade intra-medium e na migração sígnica inter-media), doravante o universo de referência do consumo imaterial, pré-simbólico, imaginário e, a esse título, do que supostamente é o mundo e do que nele ocorre.

\section{Espaço público de partilha e de resposta}

O espaço público, na acepção do presente estudo, nomeia a circunferência mediática do comume da experiência comunizada, marcada pela propensão ao ser e estar junto, bem como ao agir segundo o princípio do gregarismo. ${ }^{6}$

Esse campo de atuação equivale ao largo perímetro de (a) disponibilização gratuita de bens simbólicos e partilha consciente [idéias, softwares, posicionamentos etc.), (b) de compartilhamento orientado (de projetos sociais em rede, intencionalidades declaradas, experiências em grupo etc., de que são exemplos (diferentes em natureza) as comunidades virtuais e redes de relacionamento, a escrita colaborativa e a chamada "Web 2", (c) de intervenções pontuais politizadas (mediante mobilização, moções públicas e abaixo-assinados online, devassamento de sistemas etc.), (d) de interacionismo simbólico aleatório (em chats, listas de discussão, SMS etc.), (e) de participações fragmentárias regidas por motivação de seriedade e contribuição opinativa (inserções live em programas de rádio e televisão, de posts/comments etc.), a título de dialogia desprovida de finalidade (profissional ou não) organicamente estabeleci$\mathrm{da}$, e assim por diante, independentemente de tais procedimentos terem ou não relação (ao menos para o que importa à presente reflexão) com a disseminação de interesses privados no contexto público.

Para destacar um dos itens acima, em relação ao cyberspace (mas também a redutos off-line), a categoria do espaço público abrange hoje, fundamentalmente, práticas sociais subordinadas a dois princípios articulatórios: (a) o dom, na perspectiva da dádiva orientada à alteridade, da despensa improdutiva, reminiscência transcultural recontextualizada e renovada do potlatch, desprovida com efeito do aspecto de desafio ostensivo ao outro (Mauss, 1974; Bataille, 1975; Baudrillard, 1976; Caillé, 1989, 2002; Nicolas, 1986; Godbout, 1992), experiência caudatária da troca simbólica desprovida de interesse de lucro, da partilha não-econômica, livre sobretudo do mo- delo capitalista do valor de troca; e (b) a resposta imediata e orientada em prol da salvaguarda ou defesa de direitos historicamente conquistados e legalmente reconhecidos, bem como a propugnação de novos deles, mesmo em conflito com os aparatos institucionais e forças conservadoras.

\section{Esfera pública de discussão}

A categoria da esfera pública ${ }^{7}$ denomina, por sua vez, a conformação sociocultural e política de um campo exclusivamente (auto)reflexivo e relacional (não necessariamente racional, quer no sentido cartesiano, quer no da metafísica ocidental mais longeva), típico de grupos de sujeitos voltados para a interlocução sistemática e continuada de temas atuais e/ou relevantes da cena pública e do espaço público, debate que, encerrando acentuado valor público, tenha, em sua na natureza e na proporção de seus resultados, utilidade social-histórica e cultural de alguma ordem para a vida de relação (em âmbito regional, nacional ou internacional).

Essa esfera pública assimila-se a uma circunscrição de dialogia programática, de atuação reflexiva desdobrada e argumentada, de competência linguística em ato, demonstrada, todo um domínio de serenidade satisfatória, aberta ao socialhistórico, plena de memória cultural e compatível com a experiência conjunta de uma discussão intelectual articuladora de temporalidades objetivas e subjetivas (o passado vivo no presente, com seu potencial de iluminação, e o futuro vívido agora, atado a consequências antecipáveis).

Esses traços lembram, centralmente, a proposta de Habermas $(1984 ; 1987)$ a respeito da esfera pública genuína e da ética da ação comunicativa, baseadas em competência cognitiva mais explanadora e explicativa do que normativa e peremptória, exceção feita ao fato de o desenvolvimento exitoso da esfera aqui definida não depender - conforme antes sinalizado - exclusivamente do modelo lógico da razão ocidental (legein, nos termos de Castoriadis (1982, pp. 259-313)), compreendendo, pois, outras faculdades conscientes (como a emoção e a intuição, caucionárias da atuação e expressão humanas).

Do ponto de vista da mediação tecnológica, essa ambiência de atuação se bifurca em (a) esfera pública em rede, processada a partir de redutos glocais em tempo real, válido para todos os interlocutores; e (b) esfera pública presencial, não articulada pela instantaneidade mediática, instaurada no tempo ordinário, simultâneo ou diferido 
dos participantes. São exemplos relativos dessas variantes os fóruns de discussão online frequente e efetiva, os debates públicos alentados da imprensa (preferencialmente escrita), tecidos diaa-dia, em refração fragmentária e repercussão intermediática (rádio, TV e Internet); os congressos (científicos ou não) com debates vívidos (não ritualizados), mormente voltados para o assentamento de propostas públicas ou moções de posicionamento de referência ${ }^{8}$, e assim por diante.

\section{Recontextualização das três configurações do simbólico}

$\mathrm{Na}$ realidade, no contexto da organização mediática do social egressa do final da Segunda Guerra Mundial, em particular no estirão tecnológico mais avançado dos anos 70 em diante, abrangido pela categoria da cibercultura, essas três configurações tecnoculturais do simbólico - deve-se enfatizar - imbricam-se umas sobre as outras e mesmo se sobredeterminam, emaranhando-se muitas vezes, ao modo seja policoncêntrico, seja por justaposição flexível, e no limite se realimentam às custas da autodissolução ou autoanulação temporária de uma na outra. Em certa medida, elas são separáveis - como sói dizer-se - apenas por esforço de apreensão e abstração analíticas, e isto mesmo para efeito de testemunho circunstanciado de sua nova hibridação contemporânea, conforme especificado adiante.

A exemplo do metabolismo contextualmente duplicado da esfera pública de discussão, as duas outras configurações processam-se dentro e fora das redes comunicacionais, isto é, na linha de refração que se estende da vivência sígnica da visibilidade mediática às experiências concretas nos redutos (abertos, fechados ou mistos, comuns ou individualizados) do urbano convencional, e vice-versa. Módulos de ação cultural pertencentes à cena pública e que envolvem debates temáticos (por exemplo, no rádio ou na TV) simulam, ostensivamente, esferas públicas de discussão. Muito do espaço público, no que tange à reação social imediata a atentados contra direitos adquiridos, se tornou parte necessária da cena pública.

Do ponto de vista teórico-analítico, entretanto, não se deve confundir a cena pública com o espaço público e, menos ainda, com a esfera pública, nos termos demarcados neste estudo. Por razões socioculturais evidentes, a esfera pública, por exemplo, de par com o espaço público, se encontra formalmente "alagada" pelos fluxos da cena pública e pelos fatos do espaço público. Entretanto, com ambos jamais se confunde, por força de tensão fundamental e imanente, sustentada pela eticidade de seus procedimentos e de seu questionamento orientado. Como não poderia deixar de ser, imperam conflitos nas três configurações: pode-se, com efeito, dizer, fundamentalmente, em torno do que é mais flagrante e menos discutível, que, enquanto na cena pública a tônica do embate gravita em torno do tempo de superexposição, no espaço público ela se alimenta, com gravidade legítima, da resistência ao eventual desaparecimento de valores universais (liberdade, solidariedade, salvaguarda do adquirido, reparação justa etc.) e, na esfera pública, (ela se alimenta) de ideias e argumentos para convencimento democrático, independentemente de o procedimento alcançar consenso ou dissenso.

De modo diagramático - sob todos os riscos dos esboços esquemáticos (válidos, de toda forma, no caso, para sinalizar o núcleo de diferenças patentes) -, a cena pública, reino presenteísta do simulacro, é entrecortada, por todos os poros, pelo regime da encenação e da simulação (Baudrillard, 1976; 1981). O espaço público, dimensão de altruísmo e de resistência lastreada, é torneada pela ética da solidariedade informal e nãoregulável (não importando a rostidade do outro), da história convivial e do olvido impossível. Por sua vez, a esfera pública é marcada pela exigência de compreensão do social-histórico e, nele, do objeto tomado em consideração.

Esses apontamentos - feitos do ponto de vista teórico-analítico, grife-se -, não dispensam, no entanto, o reconhecimento do estado da arte propriamente empírico das três configurações na civilização mediática avançada. Nessa direção, a matéria apresenta aspectos idiossincráticos cuja relevância, se descurada, compromete a necessária atualização da percepção teórica e da epistème. Décadas após o desenvolvimento da indústria cultural teorizada por Adorno e Horkheimer (1970, p. 146-200), quando nem mesmo a TV havia dado mostras de capitanear os media de massa vigentes na década de 50 do século $X X$, a cena pública de promoção e autopromoção, autossustentada socialmente como macrocinturão estrutural de uma visibilidade mediática que pretensamente define o que existe e o que não existe para a percepção cotidiana, acabou por vigorar como o mainstream em que se transformou majoritariamente o espaço público tratado por Habermas (1984). 
Por seu turno, a esfera pública de discussão, a contar por indicadores há muito correntes e que se espalham a olhos vistos, apresenta-se, cada vez mais, como (a) espaço público de convivência positivamente tácita, de tipo marcantemente estésico, próprio da pragmática do afeto, na tônica pré-simbólica de um estar-junto desobrigadamente valorizado, propositalmente nãopermanente, ou de um agrupamento contextual e temporário não programaticamente constituído (na rede ou fora dela) (Maffesoli, 1987; 1997; Sodré, 2006); e (b) como espaço público de partilha protorracional (isto é, semi- ou pré-argumentativo, sem usuais exigências de pico nesse tocante) de situações, experiências, ações e resultados. Em ambos os casos, comparece um modo de disporse à alteridade que, longe das regras da linguagem rigorosamente seguidas, lembra, em termos de propensão comportamental, a despesa improdutiva e imaterial anteriormente referida.

\section{Obliteração estrutural da esfera pública no cyberspace}

Em relação ao tema nuclear da presente reflexão, essa última metamorfose cifra, sintomaticamente, o que de mais relevante se implica no domínio do público no cyberspace - ao menos em seu estirão hipermediático. $\mathrm{O}$ processo envolve tanto o modelo predominante de imaginário tecnológico - responsável, em última instância, pela instauração social-histórica de dispositivos digitais, interativos e virtuais de relações sociais -, quanto os modos correntes de apropriação sociocultural e/ou política desses recursos, modos que sofrem a inflexão de tendências estruturais (permanentes) ou conjunturais (reversíveis) da época.

\section{Características da fatoração tecnológica e empírica relativamente à defecção da esfera pública de discussão no cyberspace}

A fatoração tecnológica e empírica correspondente ao que aqui se testemunha em linhas gerais (sob todas as penalidades teóricas) consta partout, passível, por tão óbvia, de simples reconhecimento, sem descarte da correlata checagem por pesquisa empírica, certamente útil. Com efeito, um sucinto mapeamento comentado das principais plataformas, canais e dispositivos interativos de troca (em tempo real ou diferido) atualmente disponíveis (vinculadas tanto à "Web 1.0", quanto à "2.0") talvez seja primeiramente conveniente (a título de demonstração necessária) e auxilie a formação de uma imagem sugestiva a respeito.
(1) E-mails, tomados stricto sensu, como modalidade eletrônica (diferida) de correspondência postal, são essencialmente destinados a trocas tetê-à-tête e, portanto, impróprios a contextos públicos, exceto quando inseridos em lista coletiva (conforme item 11, abaixo) e ativados de modo conjunto.

(2) A dinâmica dos chats (de todos os tipos e em seja qual reduto virtual for) padece per se do frenesi de procedimentos sobre o teclado e sobre a tela, bem como da limitação espacial para as intervenções destinadas aos interlocutores.

(3) Portais e sites constituem, em geral, boas condições de base para a instauração de esferas públicas de discussão, mas, a rigor, iniciativas nesse sentido rareiam.

(4) O Second Life - a plataforma virtual capaz de absorver, em cenários tridimensionais, representações pessoais virtualmente objetalizadas (os chamados avatares) -, embora não tenha mostrado totalmente a que veio, esgota-se no ludismo de vivências de teor mais praticista que obviamente teórico-cognitivo.

(5) Redes de relacionamento como o Orkut, o MySpace e o Facebook têm, como a própria catalogação oficial o indica, finalidade diversa da reflexão compartilhada, da demonstração argumentativa e da discussão orientada. Perfis fakes não são, de toda forma, identitários e producentes a essa esfera pública.

(6) Guardadas as diferenças de natureza sociotécnica, essa incompatibilidade abrange, por motivos óbvios, fotologs e videologs, games (de todos os tipos, inclusive os mais educacionais) e o YouTube, plataforma virtual de videoinserção multilateral avessa a experiências coletivas discursivas em tempo real.

(7) O Twitter, uma extensão dos chats com campos para intervenção severamente constrangidos (a 140 toques), é, da mesma forma, pressuposta e tecnologicamente, contraproducente a qualquer dinâmica próxima da reflexão discutida.

(8) Dispositivos de áudio e/ou videoconferência como Skype e ooVoo poderiam fazer as vezes funcionais dos portais e sites. Não obstante, por problemas técnicos recorrentes (normalmente devidos a incompatibilidades de hardwares e softwares e a diferenças de ve- 
locidade de rede), envolvendo os terminais em jogo, ou por ausência de hábito de apropriação social compatível, tais recursos têm sido subutilizados, ao serem socialmente imputados a âmbitos setoriais, quando não isolados. Semelhante observação se valida para o dispositivo ipod, com alto potencial de velocidade e fluidez simbólica (inscrito em todo procedimento de oralidade), mas inteiramente inaproveitado em escala social por apropriações condizentes com a formação de esferas públicas.

(9) A Wikipedia - biblioteca virtual nutrida por conteúdos gerados colaborativamente pelos próprios usuários - constitui universo fervilhante de intervenções temáticas e desenvolvimentos argumentativos, mas não contempla a estrutura e dinâmica básicas de uma esfera pública de discussão ao impossibilitar tecnicamente o estar junto necessário e a interlocução pública simultânea ou diferida.

(10) A tendência dominante de fazer certos contextos do cyberspace perpassar aparelhos celulares esbarra nas limitações físicas da interface destes; enquadra-se no que, antes de tudo, deveria ser abolido e transformado, a fim de realmente possibilitar uma esfera pública: reflexão, discussão, questionamento e transmissão do pensamento, no nível de aprofundamento requerido, não cabem nem podem se processar em 20 ou 30 centímetros quadrados. Tal impossibilidade - lembre-se - leva de roldão SMSs e torpedos.

(11) A rigor, diante da empiria infotecnológica vigente, os contextos mais próximos e teoricamente potencializadores da esfera pública seriam as listas de discussão, os mailing lists com destinatários declarados e a rede de blogs.

(11a) Nas listas de discussão e mailing lists, são comuns fluxos de debate temático que emplacam considerações, consensos e dissensos próprios de uma esfera pública. Com a mesma força, no entanto, costumam, em geral - no caso das listas com maior volume de cadastramentos -, envolver ativamente participantes em número bem mais reduzido em proporção ao conjunto de participantes. Silêncios operacionais e, em particular, o hiato (muitas vezes, longo) entre eles - não-participação coletiva similar a uma "deserção aleatoriamente coincidente", a conferir ao contexto que media os interlocutores o aspecto de vazio estrutural ou, se se quiser, de "buraco negro", déficit de sociabilidade em bloco, como tal insondável - são, nesse sentido, mais significativos que as temporadas de participações profusas. Processos de discussão desencadeados cedo se interrompem, sem terem sido levados às últimas consequências, e são retomados adiante, ao calor de oportunidades contextuais, às vezes por remissão eventual no bojo de outro influxo temático. Mesmo nos casos de listas mais organizadas, observa-se a ausência do caráter programático e sistemático que talha, bem ou mal, uma esfera pública de discussão. Em apreciação analítica mais positiva, as listas combinam, no limite, com a idéia de esferas públicas temporárias, instauradas, de quando em vez, para resolução de problemas concretos ou consideração de assuntos relevantes ou prementes, vias que conseguem articular maiorias de interesses subjetivos e agendas individuais. Fluxos sazonais em estruturas permanentes: dissolvem-se para renascer adiante, às vezes de modo intempestivo, e assim sucessivamente.

(11b) Blogs dispõem de mesmo vigor para a instauração de esferas públicas de discussão. Não obstante, um rastreamento sistemático e amiúde em centenas de exemplares diferentes da chamada "blogosfera" - como ficou conhecida a sua refração comunitária multilateral, em âmbito nacional e internacional - é, com efeito, suficiente para levar a conclusão diversa. A "blogosfera", de par com as mencionadas listas, constitui certamente um macroespaço público de partilha, resposta e resistência, mas não propriamente uma esfera pública, na acepção empregada neste estudo.

(11c) Nos três casos - listas e blogs -, as argumentações (mesmo quando na qualidade de teorizações) se põem, com o concurso da consciência autoral, sempre insuficientes ou incompletas ou, na maioria dos casos, por razões variadas, sobremaneira lacônicas, mesmo quan- 
do positivamente lapidares. De escultura mais normativa e peremptória do que explanadora ou explicativa (o que inverte os valores de uma esfera pública) e de caráter majoritariamente empirista e funcionalista, menos teórico-epistemológico (inclusive em sequências não diretamente vinculadas ao atingimento de fins específicos), os três dispositivos acabam, infelizmente, por condenar ao relento - o que, enfim, ninguém o deseja - a profundidade de campo requerida. Por certo, polêmicas são provocadas e mantidas por determinado tempo, mas não se pode dizer acompanhadas da verticalidade aguardada. (As mobilizações coletivas em torno de uma causa - por vezes, envolvendo centenas e centenas de militantes e simpatizantes -, conseguidas mediante utilização de recursos digitais diferentes (atualmente móveis, como o celular e o laptop), têm, elas mesmas, em sua fenomenologia processual, significado social-histórico mais profundo que o alcance dos fluxos conteudísticos nos cenários mais promissores relativamente a uma esfera pública de discussão). São fatos que, por dever de ofício, cabe à teoria social constatar, sem desalento: se os ambientes virtuais mencionados são certamente públicos, a lógica da reflexão programática e sistemática está, em geral, ausente.

(12) No mais, plataformas especializadas, acadêmicas ou não, destinadas ao escoamento público de artigos abrigam, em tese, excelentes discussões temáticas - é significativo o povoamento da rede nesse sentido -, mas o debate vivo, em regime multidirecional simultâneo, que alimenta uma esfera pública, fica no sopé da fronteira eletrônica. $\mathrm{O}$ contexto se apresenta por demais "mudo" e "inaudível" para se falar da existência de uma esfera similar.

(13) Séries de comments sobre posts em blogs e, em especial, sobre os referidos artigos não têm, no conjunto, por sua natureza intermitente (quando não esporádica) e sucinta, força suficiente para sustentar a densa atmosfera de pensamento de uma ambiência de discussão, nos termos aqui consideradas.
(14) Moções online de repúdio, quando já circulantes, envolvem, em geral, apenas compreensão imediata e decisão de adesão ou não - a rigor, estão um passo além da troca pública viva do pensamento.

(15) Em suma, as comunidades virtuais - essa nomenclatura tão generosa quanto positivista, por denotar o altruísmo (aqui, no sentido de dar-se ao comum) da relação social e eliminar, ao mesmo tempo, o seu caráter tensional, subentendendo, pelo absolutismo do primeiro valor, que nesses contextos impera sempre harmonia espontânea - poderiam ser o terreno por excelência para a implantação permanente e desdobramento continuado de esferas públicas. Imperam, entretanto, no caminho, todas as injunções relatadas, aparentemente incontornáveis. A defecção estrutural observada jamais deve ser atribuída a especificidades e virtudes dos próprios interlocutores envolvidos. Diz antes respeito às condições gerais de suas respectivas vidas (conforme consideração abaixo) e, paradoxalmente, até mesmo à natureza e funcionalidade do próprio meio ou dispositivo infotecnológico envolvido.

Vez por outra, vive-se (ou se tem notícias sobre) uma discussão temática setorial e consistente - bem dito, da monta intelectual de uma esfera pública - no cyberspace. Compreende o mesmo notar que uma esfera pública sempre ativa é excepcionalmente identificada na rede. Com a licença da metáfora, tais evidências chegam mesmo a cumprir função heróica (à falta de melhor expressão) ao resistirem à inexorabilidade da morte histórica tendencial de seu substrato - e, não por outro motivo, referendam a tese principal da presente reflexão -; ao menos, adiam a constatação derradeira de que a esfera pública de discussão desapareceu por completo, recolhendo seus próprios rastros.

\section{Pressão sociodromocrática difusa, tempos pós-utópicos e crepúsculo social-histórico da razão}

$\mathrm{Na}$ base da múltipla causação sociocultural da defecção apontada, sobreleva-se, sem dúvida, a vigência, em todos os domínios - do tempo de trabalho ao tempo livre -, do imperativo dromocrático. No entremeio das diferenças dos modos de apropriação social das tecnologias e redes digitais e no quadro de fundo da destinação 
sociocultural das subjetividades para a cena pública, para o espaço público e/ou para a esfera pública, repousa, entre outros aspectos típicos, sobretudo educacionais, profissionais e pessoais, a questão crucial da relação com o tempo, em termos tanto quantitativos, quanto qualitativos.

Pressões sociodromocráticas difusas modulam fortemente - violentam ou adulteram, se se quiser, em registro mais enfático e controverso - a apropriação social das plataformas, canais e dispositivos interativos. (De toda forma, nada é, como valor social invisível e absoluto, como sprit du temps cibercultural, mais identitário a tais apropriações do que esse imperativo.) A aceitação tácita da velocidade como valor pragmático de norteamento subjetivo potencializa, de fato, nos contextos interlocutórios virtualizados, a expressão lacônica e intermitente até o limite da insuficiência argumentativa e da incompletude linguística (abrindo flanco para desentendimentos interpares por dubiedades ou ambiguidades de sentido), como, de resto, (até o limite também) da precariedade, senão da interlocução e da compreensão mútua, ao menos do principal em jogo, o debate alentado, sua seriedade e sua credibilidade (tanto internas quanto externas) - fatores hoje implicados na dispersão e esgotamento das energias coletivas responsáveis pela dinâmica regular e mínima de uma esfera pública de discussão.

No entremeio das diferenças dos modos de apropriação social das tecnologias e redes digitais e no quadro de fundo da destinação sociocultural das subjetividades para a cena pública, para o espaço público e/ou para a esfera pública, repousa, entre outros aspectos típicos, sobretudo educacionais, profissionais e pessoais, a questão crucial da relação com o tempo, em termos tanto quantitativos, quanto qualitativos.

A dromocracia cibercultural - o regime social predominante e imperceptível da velocidade digital na fase atual do capitalismo (Trivinho, 2007) - sempre foi, toda ela, mais compatível com práticas e reações imediatas do que com reflexões partilhadas, argumentadas e demonstradas. $\mathrm{Na}$ experiência predominantemente conservadora e utilitária das tecnologias e redes digitais, essa evidência encerra a própria significação social- histórica da interatividade. Reflexão custa: demanda experiência vertical do tempo e escuta atenta do pensamento, que, por seu turno, pressupõem, em contrapartida, serenidade contextual e subjetiva, como condição sine qua non de trato relacional (no caso, virtual) com a e de respeito à alteridade.

A cena pública e o espaço público, guardadas as suas diferenças de natureza e finalidade, são empáticas à aceleração generalizada da existência e experiências citadinas. Para a esfera pública de discussão, com efeito, velocidade é entropia. Tal aceleração, de par com a saturação subjetiva e corporal das singularidades dela decorrente, reduz, no fundo, as possibilidades de esfera pública no cyberspace a um processo amorfo de desracionalização progressiva.

Além do imperativo dromocrático, contribui, evidentemente e com ênfase, para a obliteração estrutural da esfera pública no cyberspace outro sobrecondicionador de época: os pendores pósutópicos típicos da atmosfera pós-moderna, no sentido estrito de um tempo de cheque-mate longitudinal das grandes visões teleológicas de mundo (Lyotard, 1986). Não por acaso - é o que se nota, até prova consistente em contrário -, o domínio do público no cyberspace, no que concerne tanto à empiria tecnológica envolvida, quanto as formas predominantes de sua apropriação social, escapa àquele antigo eixo, o da razão, na qualidade de faculdade subjetiva associada erroneamente de forma exclusiva - ao desenvolvimento da reflexão, da retórica e da discussão.

Depois das grandes revoluções sociais, lastreadas em metanarrativas políticas, econômicas, religiosas e filosóficas, de direita ou de esquerda - utopias que, além de não terem cumprido as suas promessas de origem, restauraram, em novas bases, a barbárie que pretendiam abolir -, uma lassidão social-histórica incontornável acabou por se impor no horizonte da razão (esta pedra angular da ciência e da técnica mobilizada em tantas guerras tecnológicas e implicada na deterioração progressiva das condições do planeta), com efeitos concretos e granulados na vida cotidiana, tanto na subjetividade prática, quanto especialmente na sensibilidade de mundo: a credibilidade histórica e cultural da razão (e, com ela, a da ciência e da técnica) foi açambarcada de roldão no caudal da descrença generalizada das utopias e da noção teleológica de futuro, acidente previsível que, em escala, acabou por comprometer a própria modernidade e seu projeto, forjado 
no iluminismo francês e no liberalismo inglês do final do século XVIII (Trivinho, 2001).

\section{A manterem-se as tendências predominantes, o cyberspace põe-se, em tese e paradoxalmente, avesso à esfera pública de discussão, digna do nome.}

O "espasmo" da racionalidade discursiva e argumentativa, linguisticamente competente e suficientemente exaustiva, em sua possibilidade glocal de ponta, vinculada ao cyberspace (Trivinho, 2007), se liga, portanto, umbilicalmente, na civilização contemporânea, tanto a hipérboles operacionais surreais (velocidade sociotécnica ampliada), quanto a crepúsculos epocais de vulto (o dos tempos modernos) e a retrações aleatórias irrefreáveis (a da razão) - e, quem sabe, à própria opulência hipermediática, mais afeita ao show de momento e a frenesis de vivência que à tranquilidade necessária ao processo de maturação interlocutiva do pensamento.

A evidência desses indicadores empíricos não tem contribuído senão para uma especial constatação conclusiva: a manterem-se as tendências predominantes, o cyberspace põe-se, em tese e paradoxalmente, avesso à esfera pública de discussão, digna do nome. A obliteração estrutural dessa esfera na cibercultura é, pois, produto de toda uma época. O cyberspace, não fosse o seu desdobramento diversificado e a radicalização de seu potencial sociotécnico como espaço público de partilha, resposta e resistência, já teria se tornado, de ponta a ponta, refém da cena pública de promoção e autopromoção e, portanto, uma refração sofisticada e exclusivamente condutiva da visibilidade multimediática.

Nesses delineamentos, apresenta-se uma contradição sociocultural e transpolítica fundamental (e até agora insolúvel) da época: a infraestrutura de rede, de altíssimo potencial interativo e virtual, adequada, portanto, a todos os contextos relacionais - embora seja acessível apenas às categorias sociodromocráticas, ciberaculturadas e glocalizadas, especialmente concentradas nas megalópoles, metrópoles e cidades privilegiadas adjacentes, o que corresponde a parcela diminuta da população mundial -, seria per se suficiente para fazer reescalonar e renovar, multiplicar e mesmo radicalizar a esfera pública de discussão. Todavia, condições específicas do presente - à frente o constrangimento sociodromocrático uti- litário e a decadência pós-moderna da racionalidade (mormente para efeito de sua convalidação no cyberspace) - depreciam motivações nessa direção'.

Para todos os efeitos - registre-se, por fim, em post scriptum -, esferas públicas de discussão permanecem observáveis e implantáveis em congressos acadêmicos (científicos ou não), corporativos, governamentais e não-governamentais.

Não obstante, o que dizer da predominância de debates fragmentários e realizados "às pressas", em geral sem carta final de posicionamento social de referência, sobretudo no caso de congressos de associações científicas sustentadas com verba insuficiente e nos quais avulta, com impressionante recorrência, o abarrotamento de agendas institucionais e acadêmicas dos próprios agentes do pensamento?

Não teriam também essas mesmas esferas públicas se convertido em espaços ritualizados de discussão, tornando-a previsível? Assim, a hora não estaria madura para se rever, radicalmente, no atual estágio da civilização mediática, o modelo de base da partilha, da transmissão e do desenvolvimento do conhecimento, com esteio preferencial nos pródigos resultados de uma reflexão conjunta a respeito justamente do estado da arte do domínio do público e, em especial, da esfera pública?

\section{REFERÊNCIAS}

ADORNO, Theodor Wisenground; HORKHEIMER, Max. Dialéctica del iluminismo. Buenos Aires: SUR, 1970.

BATAILLE, Georges. A parte maldita. Rio de Janeiro: Imago, 1975.

BAUDRILLARD, Jean. Para uma crítica da economia política do signo. São Paulo: Martins Fontes, s.d.

L'échange symbolique et la mort. Paris: Gallimard, 1976. Simulacres et simulations. Paris: Galilée, 1981.

CAILLÉ, Alain. Critique de la raison utilitaire. Paris: La Découverte, 1989.

Antropologia do dom: o terceiro paradigma. Petrópolis, Vozes, 2002.

CASTORIADIS, Cornelius. A instituição imaginária da sociedade. Rio de Janeiro: Paz e Terra, 1982.

ELIOT, Thomas Stearsn. Poesia. Tradução de Ivan Junqueira. Rio de Janeiro: Nova Fronteira, 1981.

GODBOUT, Jacques T.; CAILLÉ, Alain. L'esprit du don. Paris: La Découverte, 1992.

HABERMAS, Jürgen. Mudança estrutural da esfera pública: investigações quanto a uma categoria da sociedade burguesa. Rio de Janeiro: Tempo Brasileiro, 1984.

$\overline{1987.2} \mathrm{v}$. 
LYOTARD, Jean-François. O pós-moderno. Rio de Janeiro: José Olympio, 1986.

MAFFESOLI, Michel. O tempo das tribos: o declínio do individualismo nas sociedades de massa. Rio de Janeiro: Forense-Universitária, 1987.

. A transfiguração do político: a tribalização do mundo. Porto Alegre: Sulina, 1997.

MAUSS, Marcel. Ensaio sobre a dádiva: forma e razão da troca nas sociedades arcaicas. In: Sociologia e antropologia. v. II, p. 39-184. São Paulo: EPU; EDUSP, 1974.

NICOLAS, Guy. Don rituel et échange marchand dans une société sahélienne. Paris: Institut d'ethnologie, 1986.

SODRÉ, Muniz. As estratégias sensíveis: afeto, mídia e política. Petrópolis: Vozes, 2006.

TRIVINHO, Eugênio. Redes: obliterações no fim de século. São Paulo: Annablume; FAPESP, 1998.

. O mal-estar da teoria: a condição da crítica na sociedade tecnológica atual. Rio de Janeiro: Quartet, 2001.

A dromocracia cibercultural: lógica da vida humana na civilização mediática avançada. São Paulo: Paulus, 2007.

. Visibilidade mediática e violência transpolítica na cibercultura: condição atual da repercussão social-histórica do fenômeno glocal na civilização mediática avançada. In: ANTOUN, Henrique. Web 2.0: participação e vigilância na era da comunicação distribuída. Rio de Janeiro: Mauad, 2008.

VIRILIO, Paul. O espaço crítico. Rio de Janeiro: Ed. 34, 1993a. . A inércia polar. Lisboa: Dom Quixote, 1993b.

\section{NOTAS}

1 O presente texto constitui parte de argumentação mais abrangente acerca da lógica e significação da visibilidade mediática na civilização contemporânea, referente a pesquisa financiada pelo CNPq (Bolsa de Produtividade em Pesquisa).
2 Ainda que, em geral - não se pode olvidar -, sob a agravante de todas as línguas nacionais se terem afunilado para o inglês como código linguístico majoritário.

3 O tema é retomado no item 3 do próximo tópico.

4 A argumentação previa mais uma tese, que a necessidade de edição do presente texto não permitiu incluir: a de que, apesar de tudo - contra todas as disposições antipragmáticas e niilistas em contrário -, é necessário, por dever de responsabilidade histórica e estratégia política no capitalismo contemporâneo, preservar, em essência, estrutura e funcionamento, essa esfera pública, umbral de liberdade lúcida e conjunta possível de pensamento, expressão e ação.

5 Na dupla acepção pressuposta no radical: jogo e diversão para mente e corpo, e preservação da consciência do sujeito permanentemente entretida, tão alerta quanto nãoalienada, como numa doce dissuasão impercebida, de tão simbolicamente eficaz.

6 Merecem lembrança, nesse contexto, os registros de Maffesoli $(1987,1997)$ a respeito da partilha do sensível como desejo e valor contemporâneos.

7 A presente reflexão joga com uma sutileza epistemológica idiossincrática entre espaço público e esfera pública, nuança propositalmente encaminhada a título de apreensão de distinções intersticiais na empiria processual em questão, bem como de aproximação a ela.

8 Escapam do trecho, por motivos evidentes, os contextos educacionais convencionais e relacionais, como a dinâmica interlocutiva em sala de aula (seja de que nível for, presencial ou a distância), exceto quando o projeto pedagógico em jogo assimile o conjunto de atividades à dinâmica da esfera pública mencionada.

9 Eis porque tais condições, embora postas à luz do dia, não estão suficiente e objetivamente dadas, na perspectiva em que o marxismo as entendia. Condições históricas objetivas exigem o concurso simultâneo da consciência humana e do potencial pragmático desta, no trato das forças produtivas disponíveis. 